\title{
Control efficacy of selected natural products against chrysanthemum foliar nematode - Aphelenchoides ritzemabosi (Schwartz, 1911) Steiner \& Buhrer, 1932
}

\author{
Ocena skuteczności działania niektórych substancji i preparatów \\ pochodzenia naturalnego w zwalczaniu węgorka chryzantemowca \\ - Aphelenchoides ritzemabosi (Schwartz, 1911) Steiner i Buhrer, 1932
}

\author{
Aneta Chałańska, Gabriel Łabanowski, Robert Maciorowski
}

\section{Summary}

In 2011-2012 the effects of azadirachtin (NeemAzal T/S), abamectin (Vertimec $018 \mathrm{EC}$ ), glycol-aqueous extract of Quillaja saponaria (Quillaja Extract), aqueous extracts of minced garlic, aqueous extracts of marigold roots and leaves, aqueous extract of salvia leaves in the control of chrysanthemum foliar nematode Aphelenchoides ritzemabosi (Schwartz, 1911) Steiner \& Buhrer, 1932 were examined. Efficacy of these products was determined in the laboratory test on chrysanthemum leaves, and on clematis and anemone plants infested by $A$. ritzemabosi in greenhouse experiments. The highest mortality of chrysanthemum foliar nematode on chrysanthemum leaves was obtained after application of $Q$. saponaria extract and minced garlic extract. In greenhouse conditions the highest effectiveness had $Q$. saponaria extract (above 90\%), statistically significant in trial on anemone plants. Unfortunately, application of this product resulted in phytotoxicity symptoms on plants.

Key words: Aphelenchoides ritzemabosi, control, natural substances

\section{Streszczenie}

W latach 2011-2012 oceniano skuteczność działania azadirachtyny (NeemAzal T/S), abamektyny (Vertimec 018 EC), wodnoglikolowego ekstraktu z Quillaja saponaria (Quillaja Extract), wyciągu z miazgi czosnkowej oraz wyciągów z korzeni i liści aksamitki, i liści szałwii w warunkach laboratoryjnych na liściach chryzantemy oraz w szklarni na powojniku i zawilcu japońskim. W warunkach laboratoryjnych istotnie najwyższą śmiertelność węgorka chryzantemowca uzyskano po zastosowaniu ekstraktu z Q. saponaria i wyciągu z miazgi czosnkowej. W warunkach szklarniowych spośród testowanych substancji najwyższą śmiertelność nicieni (powyżej 90\%) uzyskano po zastosowaniu ekstraktu z Q. saponaria, udowodnioną statystycznie w doświadczeniu na zawilcu. Niestety produkt ten wykazywał na badanych roślinach fitotoksyczność.

Słowa kluczowe: Aphelenchoides ritzemabosi, zwalczanie, preparaty pochodzenia naturalnego

\section{Instytut Ogrodnictwa}

Zakład Ochrony Roślin Ozdobnych

Waryńskiego 14, 96-100 Skierniewice

aneta.chalanska@inhort.pl 


\section{Wstęp / Introduction}

W Polsce wegorek chryzantemowiec Aphelenchoides ritzemabosi (Schwartz, 1911) Steiner i Buhrer, 1932 od wielu lat jest znanym i powszechnym szkodnikiem truskawki (Szczygieł 1967) i chryzantemy (Baranowski 1976), a także występuje na kilkunastu gatunkach bylin i krzewów ozdobnych produkowanych w szkółkach (Chałańska i Łabanowski 2010).

Wcześniejsze badania dotyczyły możliwości zwalczania węgorka chryzantemowca na chryzantemie klasycznymi nematocydami podawanymi $\mathrm{w}$ formie opryskiwania (Baranowski 1982) lub doglebowo (Wojtowicz i Łabanowski 1993, 1995). W badaniach tych stwierdzono wówczas właściwości nicieniobójcze następujących substancji czynnych: diazinon (Basudin 25 EC), fenitrotion (Owadowos płynny 50), triazofos (Hostathion 40 EC), oksamyl (Vydate L, Vydate $10 \mathrm{G}$ ), metomyl (Lannate $25 \mathrm{WP}$ ), metyloparation (Wofatox Spritzmittel), fenamifos (Nemacur $10 \mathrm{G}$ ), aldicarb (Temik $10 \mathrm{G})$, karbofuran (Furadan 5 G, Diafuran 350 L, Diafuran 5 G, Chinofos $5 \mathrm{G})$. Stosowanie większości z tych substancji jest obecnie zakazane. Ponadto w Polsce począwszy od dnia 1 stycznia 2014 r. wszystkich profesjonalnych użytkowników środków ochrony roślin obowiązywało będzie stosowanie zasad integrowanej ochrony roślin, co wynika z postanowień art. 14 dyrektywy 2009/128/WE oraz rozporządzenia nr 1107/2009/WE (Anonymous 2009). Tym samym nastapi znaczne ograniczenie stosowania chemicznych środków ochrony roślin, które należy zastąpić substancjami m.in. pochodzenia naturalnego.

Szereg gatunków roślin zawiera olejki eteryczne, terpenoidy i alkaloidy, które mają właściwości antagonistyczne w stosunku do nicieni pasożytniczych (Sangwan i wsp. 1985; Insunza i Valenzuela 1995; Wuyts i wsp. 2006; Thoden i wsp. 2007; Elbadri i wsp. 2008), choć modyfikują je metody ekstrakcji $\mathrm{z}$ materiału roślinnego (Kimpel i wsp. 2011).

Celem badań była ocena przydatności wodnych wyciągów roślinnych i preparatów pochodzenia naturalnego do zwalczania węgorka chryzantemowca występującego na roślinach ozdobnych.

\section{Materiały i metody / Materials and methods}

Badania prowadzono w 2011 r. w warunkach laboratoryjnych na chryzantemie wielkokwiatowej odmiany Bislet, a w 2012 r. na powojniku odmiany Anita i zawilcu japońskim odmiany Prinz Henrich w szklarni doświadczalnej Instytutu Ogrodnictwa w Skierniewicach. Do doświadczeń przygotowano następujące preparaty: wodny wyciąg z ząbków czosnku pospolitego (Allium sativum L.), wodny wyciąg $\mathrm{z}$ liści i korzeni aksamitki rozpierzchłej niskiej (Tagetes patula nana L.), wodny wyciąg z liści szałwii omszonej (Salvia nemorosa L.), roztwór gotowego preparatu z kory mydłoki właściwej (Quillaja saponaria Molina), roztwór preparatu botanicznego zawierającego azadirachtynę (Azadirachta indica A. Juss.), roztwór preparatu zawierający abamektynę jako toksyny promieniowca glebowego Streptomyces avermitilis.
Wyciagi wodne z ząbków czosnku, korzeni aksamitki, liści aksamitki i liści szałwii przygotowano we własnym zakresie, używając $25 \mathrm{~g}$ świeżego materiału roślinnego na litr wody, zgodnie z metodyką Dąbrowskiego i Seredyńskiej (2007). W doświadczeniach użyto $1 \%$ roztwór preparatu handlowego NeemAzal T/S (azadirachtyna $10 \mathrm{~g} / \mathrm{l})$ firmy Trifolio-M $\mathrm{GmbH}$ oraz $0,1 \%$ roztwór preparatu Vertimec 018 EC (abamektyna $18 \mathrm{~g} / \mathrm{l}$ ) firmy Syngenta Crop Protection AG i 50\% roztwór preparatu handlowego Quillaja Extract (2,2\% ekstraktu wodno-glikolowego z kory mydłoki właściwej) firmy Provital S.A.

Ocenę laboratoryjną działania wyciągów roślinnych i preparatów przeprowadzono na podstawie wyników testu szalkowego w komorze hodowlanej w temperaturze $20 \pm 1^{\circ} \mathrm{C}$. W każdej szalce umieszczono 6-10 liści chryzantemy porażonych przez węgorka chryzantemowca, wcześniej zanurzanych $\mathrm{w}$ jednym $\mathrm{z}$ przygotowanych roztworów przez 30 sekund, po 4 szalki na każdy wyciąg lub preparat.

Doświadczenia szklarniowe założono w układzie całkowicie losowym w 4 powtórzeniach. Każdym wyciagiem wodnym lub roztworem preparatu opryskiwano jednokrotnie 4 rośliny powojnika lub dwukrotnie, w odstępie 3 dni 4 rośliny zawilca japońskiego porażone przez węgorka chryzantemowca, zużywając około $35 \mathrm{ml}$ cieczy użytkowej/powtórzenie. W każdym terminie oceny pobierano po 2 liście z każdej z 4 roślin powojnika i po jednym liściu $\mathrm{z}$ każdej $\mathrm{z}$ roślin zawilca japońskiego. Zabieg opryskiwania roślin (T) w przypadku powojnika wykonany był $\mathrm{w}$ temperaturze $19^{\circ} \mathrm{C}$ i wilgotności względnej powietrza $71 \%$. Na roślinach zawilca pierwszy zabieg opryskiwania roślin (T1) wykonany był w temperaturze $13,1^{\circ} \mathrm{C}$ i wilgotności względnej powietrza $66 \%$, a drugi zabieg opryskiwania roślin (T2) wykonany był w temperaturze $20,3^{\circ} \mathrm{C}$ i wilgotności względnej powietrza $42 \%$.

Nicienie z liści ekstrahowano zmodyfikowaną metoda Baermana i liczono żywe osobniki pod mikroskopem stereoskopowym przy 32-krotnym powiększeniu. Nicienie liczono przed zabiegiem oraz 3 i 7 dni po zabiegu, za każdym razem ekstrahując je $\mathrm{z} 4$ liści $\mathrm{z}$ każdego powtórzenia, za wyjątkiem doświadczenia szalkowego, gdzie liczbę nicieni przed zabiegiem oszacowano na podstawie 10 liści.

Zebrane dane odnoszące się do liczebności zostały poddane transformacji Boxa-Coxa, z przesunięciem zmiennej wyjściowej ze względu na występowanie obserwacji zerowych. Następnie wyniki opracowano za pomoca analizy wariancji. Średnie dla wariantów w ramach poszczególnych terminów pomiarów porównywano z wariantem kontrolnym za pomocą jednostronnego testu Dunnetta. Średnie dla terminów pomiarów porównywano testem Duncana. Ponadto na podstawie liczby nicieni obliczono efektywność działania preparatów (w \%) za pomocą wzoru Abbotta. Do oceny skuteczności zwalczania nicieni przyjęto kryteria skuteczności działania preparatów zgodne z Rozporządzeniem Ministra Rolnictwa i Rozwoju Wsi z 4.08.2004 - Dz. U. Nr. 183 poz. 1890, gdzie: co najmniej $80 \%$ określa się mianem zwalczania, $60-80 \%$ to średni poziom zwalczania, 40-60\% - oznacza ograniczone zwalczanie. 


\section{Wyniki i dyskusja / Results and discussion}

W warunkach laboratoryjnych istotną skuteczność w ograniczaniu liczebności węgorka chryzantemowca wykazał ekstrakt z mydłoki właściwej oraz wyciag wodny miazgi czosnkowej. Preparaty NeemAzal T/S i Vertimec 018 EC przeciętnie powodowały śmiertelność nicieni na poziomie $40-60 \%$, chociaż po zastosowaniu tych preparatów nie wykazano istotnego spadku liczebności nicieni w stosunku do kontroli (tab. 1). Wodne wyciągi z części nadziemnych oraz korzeni aksamitki i liści szałwii nie wykazały skutecznego działania, stąd pominięto je w badaniach szklarniowych.

W doświadczeniu szklarniowym przeprowadzonym na powojniku skuteczność działania powyżej 90\% w zwalczaniu węgorka chryzantemowca uzyskano po 3 dniach od zastosowania wyciagu wodnego $\mathrm{z}$ czosnku i preparatu
Quillaja Extract oraz 74\% (średni poziom zwalczania) po zastosowaniu preparatu Vertimec 018 EC. Preparat botaniczny - NeemAzal T/S powodował śmiertelność poniżej $25 \%$. W kolejnym terminie oceny, 7 dni po zabiegu, jedynie preparat Quillaja Extract powodował śmiertelność nicieni na poziomie około 65\% (tab. 2). Jednak po zastosowaniu tego preparatu obserwowano objawy fitotoksyczności w postaci brązowych plam na liściach, a skuteczność jego działania nie została udowodniona statystycznie.

W doświadczeniu szklarniowym na zawilcu japońskim śmiertelność bliską 90\% uzyskano po 3 dniach od zabiegu po zastosowaniu preparatów NeemAzal T/S i Vertimec 018 EC, średni poziom zwalczania nicieni uzyskano po zastosowaniu wyciągu z czosnku i ekstraktu z mydłoki, nieco niższą skuteczność wykazała mieszanina wyciagu z czosnku i preparatu Quillaja Extract (tab. 3). Powtórzenie

Tabela 1. Śmiertelność węgorka chryzantemowca po zastosowaniu preparatów pochodzenia naturalnego w liściach chryzantemy. Test szalkowy - Skierniewice, 20.09.2011

Table 1. The effect of botanical products and plant extracts on the numbers of A. ritzemabosi infesting chrysanthemum leaves. Petri dish test - Skierniewice, 20.09.2011

\begin{tabular}{|c|c|c|c|c|}
\hline \multirow{2}{*}{$\begin{array}{l}\text { Preparat i stężenie } \\
\text { Extract or product and concentration }\end{array}$} & \multicolumn{2}{|c|}{$\begin{array}{c}\text { Liczba osobników/liść }^{1} \\
\text { Number of nematodes/leaf }\end{array}$} & \multicolumn{2}{|c|}{$\begin{array}{c}\% \text { śmiertelności po zabiegu } \\
\% \text { of the mortality }\end{array}$} \\
\hline & $\mathrm{T}+3^{2}$ & $\mathrm{~T}+7^{2}$ & $\mathrm{~T}+3^{3}$ & $\mathrm{~T}+7^{3}$ \\
\hline NeemAzal T/S - 1\% & 176 & 91 & 21,27 & 65,31 \\
\hline Vertimec $018 \mathrm{EC}-0,1 \%$ & 127 & 111 & 43,35 & 57,80 \\
\hline A. sativum $-2,5 \%$ & $51^{*}$ & 233 & 77,12 & 11,28 \\
\hline T. patula nana korzeń - root $-2,5 \%$ & 180 & 299 & 19,68 & 0,0 \\
\hline T. patula nana liść - leaf - 2,5\% & 287 & 209 & 0,0 & 20,31 \\
\hline S. nemorosa liść - leaf - $2,5 \%$ & 185 & 532 & 17,12 & 0,0 \\
\hline Quillaja Extract - 50\% & $71^{*}$ & $22 *$ & 69,17 & 91,46 \\
\hline Quillaja Extract - 12,5\% & 447 & 73 & 0,0 & 74,56 \\
\hline Kontrola - Untreated & 224 & 262 & - & - \\
\hline
\end{tabular}

${ }^{1}$ średnia liczba nicieni przed zabiegiem wynosiła 158 - average number of nematodes before treatment was 158

${ }^{2}$ średnie oznaczone w kolumnie gwiazdką są istotnie mniejsze w stosunku do wariantu kontrolnego według jednostronnego testu Dunnetta ( $\left.\mathrm{p}<0,05\right)-$ values marked with star in column are significant low compare to check according to one-sided Dunnett test $(\mathrm{p}<0.05)$

${ }^{3}$ co najmniej $80 \%$ : zwalczanie, 60-80\%: średni poziom zwalczania, 40-60\%: ograniczone zwalczanie - at least $80 \%$ : good level of control, 60-80\%: medium level of control, 40-60\%: limited level of control

$\mathrm{T}+3, \mathrm{~T}+7$ - liczebność nicieni 3 i 7 dni po zabiegu - number of nematodes 3 and 7 days after treatment

Tabela 2. Śmiertelność węgorka chryzantemowca na powojniku odmiany Anita. Doświadczenie szklarniowe - Skierniewice, 04.10 .2012 Table 2. The effect of botanical products and plant extracts on the numbers of A. ritzemabosi infesting clematis cultivar Anita leaves. Glasshouse experiment - Skierniewice, 04.10.2012

\begin{tabular}{|c|c|c|c|c|c|}
\hline \multirow{2}{*}{$\begin{array}{c}\text { Preparat i stężenie } \\
\text { Extract or product and concentration }\end{array}$} & \multicolumn{3}{|c|}{$\begin{array}{l}\text { Liczba osobników/liść }^{1} \\
\text { Number of nematodes/leaf }\end{array}$} & \multicolumn{2}{|c|}{$\begin{array}{c}\% \text { śmiertelności po zabiegu } \\
\% \text { of the mortality }\end{array}$} \\
\hline & PRE-T $^{1}$ & $\mathrm{~T}+3^{1}$ & $\mathrm{~T}+7^{1}$ & $\mathrm{~T}+3^{2}$ & $\mathrm{~T}+7^{2}$ \\
\hline NeemAzal T/S - 1\% & 53 & 259 & 233 & 21,2 & 0,1 \\
\hline Vertimec 018 EC $-0,1 \%$ & 61 & 85 & 304 & 74,0 & 0,0 \\
\hline A. sativum $-2,5 \%$ & 17 & 21 & 256 & 93,5 & 0,0 \\
\hline Quillaja Extract - 50\% & 29 & 18 & 87 & 94,6 & 64,9 \\
\hline Kontrola - Untreated & 42 & 328 & 247 & - & - \\
\hline
\end{tabular}

${ }^{1}$ średnie nie były istotnie mniejsze w stosunku do wariantu kontrolnego według jednostronnego testu Dunnetta (p $\left.<0,05\right)-$ values marked with star in column are significant low compare to check according to one-sided Dunnett test $(\mathrm{p}<0.05)$

${ }^{2}$ co najmniej $80 \%$ : zwalczanie, 60-80\%: średni poziom zwalczania, 40-60\%: ograniczone zwalczanie - at least $80 \%$ : good level of control, 60-80\%: medium level of control, 40-60\%: limited level of control

PRE-T - liczebność nicieni przed zabiegiem (w dniu zabiegu) - number of nematodes before treatments (in day of treatment)

$\mathrm{T}+3, \mathrm{~T}+7$ - liczebność nicieni 3 i 7 dni po zabiegu - number of nematodes 3 and 7 days after treatment 
Tabela 3. Śmiertelność węgorka chryzantemowca na zawilcu japońskim odmiany Prinz Heindrich. Doświadczenie szklarniowe Skierniewice, 19.10.2012

Table 3. The effect of botanical products and plant extracts on the numbers of A. ritzemabosi infesting anemone cultivar Prinz Heindrich leaves. Glasshouse experiment - Skierniewice, 19.10.2012

\begin{tabular}{l|c|c|c|c|c|c|c}
\hline \multirow{2}{*}{$\begin{array}{c}\text { Preparat i stężenie } \\
\text { Extract or product and concentration }\end{array}$} & \multicolumn{3}{c|}{$\begin{array}{c}\text { Liczba osobników/liść } \\
\text { Number of nematodes/leaf }\end{array}$} & \multicolumn{4}{c}{$\begin{array}{c}\text { \% śmiertelności po zabiegu } \\
\% \text { of the mortality }\end{array}$} \\
\cline { 2 - 8 } & PRE-T & $\mathrm{T} 1+3$ & $\mathrm{~T} 2+3^{1}$ & $\mathrm{~T} 2+7$ & $\mathrm{~T} 1+3^{2}$ & $\mathrm{~T} 2+3^{2}$ & $\mathrm{~T} 2+7^{2}$ \\
\hline NeemAzal T/S - 1\% & 732 & 851 & 1468 & 1077 & 88,5 & 37,1 & 38,7 \\
\hline Vertimec 018 EC - 0,1\% & 880 & 775 & 615 & 519 & 89,6 & 42,6 & 70,5 \\
\hline A. sativum - 2,5\% & 944 & 1714 & 642 & 626 & 76,9 & 40,0 & 64,4 \\
\hline Quillaja Extract - 50\% & 1173 & 2674 & $95 *$ & 105 & 64,0 & 91,1 & 94,0 \\
\hline A. sativum 2,5\% + Quillaja Extract 50\% & 917 & 3233 & 174 & 219 & 56,4 & 83,7 & 87,5 \\
\hline Kontrola - Untreated & 1211 & 7420 & 1071 & 1758 & - & - & - \\
\hline
\end{tabular}

${ }^{1}$ średnie oznaczone w kolumnie gwiazdką są istotnie mniejsze w stosunku do wariantu kontrolnego według jednostronnego testu Dunnetta (p < 0,05) values marked with star in column are significant low compare to check according to one-sided Dunnett test $(\mathrm{p}<0.05)$

${ }^{2}$ co najmniej 80\%: zwalczanie, 60-80\%: średni poziom zwalczania, 40-60\%: ograniczone zwalczanie - at least 80\%: good level of control, 60-80\%: medium level of control, 40-60\%: limited level of control

PRE-T - liczebność nicieni przed zabiegiem (w dniu zabiegu) - number of nematodes before treatments (in day of treatment)

$\mathrm{T}+3, \mathrm{~T}+7$ - liczebność nicieni 3 i 7 dni po zabiegu - number of nematodes 3 and 7 days after treatment

zabiegu po 3 dniach podniosło znacznie skuteczność działania preparatu Quillaja Extract. Zastosowany dwukrotnie istotnie obniżał liczebność nicieni, a działanie następcze na podobnym poziomie utrzymało się do $7 \mathrm{dni}$ po drugim zabiegu. Nieco niższe działanie następcze, ale na średnim poziomie zwalczania, wykazał wyciąg z czosnku i preparat Vertimec 018 EC. Działanie następcze preparatu NeemAzal T/S utrzymywało się na podobnym poziomie (tab. 3). Preparat Quillaja Extract wywołał objawy fitotoksyczności na liściach zawilca japońskiego, choć znacznie słabsze niż w przypadku powojnika.

W badaniach laboratoryjnych i szklarniowych stwierdzono, że wyciagi wodne $\mathrm{z}$ roślin o znanych właściwościach nicieniobójczych nie zawsze zwalczają węgorka chryzantemowca na chryzantemie, powojniku i zawilcu japońskim. W doświadczeniu nie stwierdzono, aby wyciąg z liści szałwii miał działanie ograniczające liczebność osobników węgorka chryzantemowa, chociaż zawiera terpenoidy, a wśród nich salwinorynę, która wykazuje działanie antagonistyczne w stosunku do nicieni (Topçu 2006; Barbosa i wsp. 2010). Wynika to prawdopodobnie stąd, że olejki eteryczne szałwii mają lepsze właściwości nicieniobójcze niż zastosowany wyciąg wodny z liści tej rośliny. Podobnie nie uzyskano skutecznego działania wyciagu wodnego $\mathrm{z}$ korzeni i liści aksamitki, chociaż zawiera $\alpha$-tertenyl (Kyo i wsp. 1990), który ogranicza występowanie niektórych gatunków nicieni w glebie (Pudasaini 2006). Podobnie ograniczenia występowania nicienia - Xiphinema index za pomocą aksamitki nie uzyskali Aballay i Insunza (2002). Azadirachtyna zawarta w preparacie NeemAzal T/S jest bionematocydem w stosunku do nicieni glebowych, głównie $\mathrm{z}$ rodzaju Meloidogyne (Akhtar 2000), ale nie udokumentowano ich w stosunku do nicieni żerujących w liściach (Jagdale i Grewal 2002). Potwierdzają to uzyskane wyniki, które wskazują jedynie na słabe i krótkotrwałe działanie preparatu NeemAzal T/S w stosunku do węgorka chryzantemowca.

Wyciąg wodny z ząbków czosnku we wszystkich doświadczeniach skutecznie ograniczał liczebność węgorka chryzantemowca. Wynika to $\mathrm{z}$ silnych właściwości biotycznych czosnku, który zawiera siarkoorganiczny związek - allicynę oddziałająca na roztocze, owady, grzyby, bakterie (Auger i wsp. 2004), a także charakteryzuje się silnymi właściwościami nicieniobójczymi (Park i wsp. 2005).

Wyniki badań potwierdziły także silne działanie nicieniobójcze ekstraktu wodno-glikolowego z $Q$. saponaria (San Martín i Magunacelaya 2005), chociaż był on fitotoksyczny $\mathrm{w}$ stosunku do powojnika i zawilca. Prawdopodobnie spowodowane było to zawartym w tym ekstrakcie glikolem, stąd należy dopracować formulację tego związku eliminując $\mathrm{z}$ niego tą substancję.

Zastosowany $\mathrm{w}$ doświadczeniach preparat Vertimec 018 EC redukował liczebność węgorka chryzantemowca, choć nie udało się wykazać istotności uzyskanych wyników. Właściwości paraliżujące abamektyny w stosunku do nicieni znane były wcześniej i wykazywane w stosunku do węgorków na roślinach ozdobnych (LaMondia 1999; Young i Maher 2000; Soika i Łabanowski 2003).

Przeprowadzone doświadczenia wykazały, że pomimo wielu przesłanek i wcześniejszych badań różnych autorów, działanie preparatów pochodzenia naturalnego jest prawdopodobnie silnie zależne od wielu czynników środowiskowych, a stąd bardzo niestabilne. Dalsze badania dotyczące tych substancji powinny określić wpływ temperatury i wilgotności powietrza na ich działanie, a także określić warunki, w jakich ich skuteczność, w zwalczaniu węgorka chryzantemowca będzie najwyższa.

\section{Wnioski / Conclusions}

1. Wyciagi wodne $\mathrm{z}$ liści i korzeni aksamitki (T. patula nana) oraz z liści szałwii omszonej ( $S$. nemorosa) nie wykazały właściwości nicieniobójczych w stosunku do węgorka chryzantemowca.

2. Ekstrakt z mydłoki właściwej i wyciąg wodny z miazgi czosnkowej wykazały właściwości nicieniobójcze w stosunku do węgorka chryzantemowca. 
3. Preparat Quillaja Extract, pomimo udowodnionej skuteczności w zwalczaniu $A$. ritzemabosi, wykazuje fitotoksyczność dla testowanych roślin i nie powinien być stosowany w formie opryskiwania liści.

Opracowanie wykonano $\mathrm{w}$ ramach zadania $\mathrm{nr} 1.40$ „Wykrywanie i oznaczanie nicieni kwarantannowych podlegających obowiązkowi zwalczania, określenie ich występowania na terytorium Polski oraz zapobieganie ich rozprzestrzenianiu się”, Programu Wieloletniego „Rozwój zrównoważonych metod produkcji ogrodniczej w celu zapewnienia wysokiej jakości biologicznej i odżywczej produktów ogrodniczych oraz zachowania bioróżnorodności środowiska i ochrony jego zasobów", finansowanego przez Ministerstwo Rolnictwa i Rozwoju Wsi.

\section{Literatura / References}

Aballay E., Insunza V. 2002. Evaluation of plants with nematicidal properties in the control of Xiphinema index on table grapes cv. Thompson Seedless in the central zone of Chile. Agric. Tec. 62 (3): 357-365.

Akhtar M. 2000. Nematicidal potential of the neem tree Azadirachta indica (A. Juss). Integrated Pest Manage. Rev. 5 (1): 57-66.

Anonymous 2009. Directive 2009/128/EC of the European Parliament and of the Council. Official Journal of the European Union, http://eur-lex.europa.eu/LexUriServ/LexUriServ.do?uri=OJ:L:2009:309:0071:0086:EN:PDF, 16 pp, accessed: 7.05.2013.

Auger J., Arnault I., Diwo-Allain S., Ravier M., Molia F., Pettiti M. 2004. Insecticidal and fungicidal potential of Allium substances as biofumigants. Agroindustria 3 (3): 367-370.

Baranowski T. 1976. Badania nad szkodliwą fauną złocieni w okolicach Poznania. Rocz. Nauk Rol., Seria E, 6 (1): 19-23.

Baranowski T. 1982. Ocena skuteczności kilku preparatów w zwalczaniu węgorka chryzantemowca (Aphelenchoides ritzemabosi (Schwartz) Steiner) występującego na złocieniach rabatowych. Prace Inst. Sad. Kwiac., Seria B, 7: 245-249.

Barbosa P., Lima A.S., Vieira P., Dias L.S., Tinoco M.T., Barroso J.G., Pedro L.G., Figueiredo A.C., Mota M. 2010. Nematicidal activity of essential oils and volatiles derived from Portuguese aromatic flora against the pinewood nematode, Bursaphelenchus xylophilus. J. Nematol. 42 (1): 8-16.

Chałańska A., Łabanowski G. 2010. Diagnostyka nicieni liściowych z rodzaju Aphelenchoides. Instrukcja wykrywania nicieni na podstawie uszkodzeń roślin ozdobnych. Agencja Reklamowo-Wydawnicza Estet, Skierniewice, 20 ss.

Dąbrowski Z.T., Seredyńska U. 2007. Characterisation of the two-spotted spider mite (Tetranychus urticae Koch, Acari: Tetranychidae) response to aqueous extracts from selected plant species. J. Plant Prot. Res. 47 (2): 113-124.

Elbadri G.A.A., Lee D.W., Park J.C., Yu H.B., Choo H.Y., Lee S.M., Lim T.H. 2008. Nematocidal screening of essential oils and herbal extracts against Bursaphelenchus xylophilus. Plant Pathol. J. 24 (2): 178-182.

Insunza V., Valenzuela A.A. 1995. Control of Ditylenchus dipsaci on garlic (Allium sativum) with extracts of medicinal plants from Chile. Nematropica 25 (1): 35-41.

Jagdale G.B., Grewal P.S. 2002. Identification of alternatives for the management of foliar nematodes in floriculture. Pest Manage. Sci. 58 (5): 451-458.

Kimpel S., Abdel-Ghaffar F., Al-Rasheid K.A., Aksu G., Fischer K., Strassen B., Mehlhorn H. 2011. The effects of different plant extracts on nematodes. Parasitol. Res. 108 (4): 1047-1054.

Kyo M., Miyauchi Y., Fujimoto T., Mayama S. 1990. Production of nematocidal compounds by hairy root cultures of Tagetes patula. Plant Cell Reports 9 (7): 393-397.

LaMondia J.A. 1999. Efficacy of insecticides for control of Aphelenchoides fragariae and Ditylenchus dipsaci in flowering perennial ornamentals. Suppl. J. Nematol. 31 (4S): 644-649.

Park I.K., Park J.Y., Kim K.H., Choi K.S., Choi I.H., Kim C.S., Shin S.C. 2005. Nematicidal activity of plant essential oils and components from garlic (Allium sativum) and cinnamon (Cinnamomum verum) oils against the pine wood nematode (Bursaphelenchus xylophilus). Nematology 7 (5): 767-774.

Pudasaini M.P., Viaene N., Moens M. 2006. Effect of marigold (Tagetes patula) on population dynamics of Pratylenchus penetrans in a field. Nematology 8 (4): 477-484.

San Martín R., Magunacelaya J.C. 2005. Control of plant-parasitic nematodes with extracts of Quillaja saponaria. Nematology 7 (4): $577-585$.

Sangwan N.K., Verma K.K., Verma B.S., Malik M.S., Dhindsa K.S. 1985. Nematicidal activity of essential oils of Cymbopogon grasses. Nematologica 31: 93-99.

Soika G., Łabanowski G. 2003. Zagrożenie upraw szkółkarskich roślin ozdobnych przez węgorka chryzantemowca i próba jego zwalczania. [Treat of chrysanthemum foliar nematode to ornamental nurseries crops and possbility to control this pest]. Prog. Plant Prot./Post. Ochr. Roślin 43 (2): 936-939.

Szczygieł A. 1967. Wstępna ocena szkodliwości nicieni z rodzaju Aphelenchoides dla truskawek w Południowej Polsce. Prace Inst. Sad. 11: 211-224.

Thoden T.C., Boppré M., Hallmann J. 2007. Pyrrolizidine alkaloids of Chromolaena odorata act as nematicidal agents and reduce infection of lettuce roots by Meloidogyne incognita. Nematology 9 (3): 343-349.

Topçu G. 2006. Bioactive triterpenoids from Salvia species. J. Nat. Prod. 69 (3): 482-487.

Wojtowicz M., Łabanowski G. 1993. Wpływ nematocydów na wzrost złocieni i rozwój węgorka chryzantemowca (Aphelenchoides ritzemabosi). Zesz. Nauk. Inst. Sad. Kwiac. 1: 139-146.

Wojtowicz M., Łabanowski G. 1995. Wpływ termicznego i chemicznego traktowania roślin matecznych złocieni na ich wzrost i porażenie przez węgorka chryzantemowca Aphelenchoides ritzemabosi (Schwartz, 1911). Zesz. Nauk. Inst. Sad. Kwiac. 2: 129-135.

Wuyts N., Swennen R., De Waele D. 2006. Effects of plant phenylpropanoid pathway products and selected terpenoids and alcaloids on the behavior of the plant-parasitic nematodes Radopholus similis, Pratylenchus penetrans and Meloidogyne incognita. Nematology 8 (1): 89-101.

Young J.E.B., Maher H.M. 2000. Evaluation of abamectin against bud and leaf nematode in hardy ornamentals. The BCPC Conference - Pests and Diseases 1: 309-314. 